\title{
METHODS OF DISINFECTION.*
}

\author{
BY W. LESLIE MACKENZIE, M.A., M.D.. \\ Medical Officer of Health of Leith.
}

I. The Speciar Problex.-The title "Methods of Disinfection" is much too comprehensive for the special problem I have been requested to put in train for discussion. On the general principles of disinfection we are, I take it, at one. Where our practices, and presumably our theories, differ is in certain special methods applied to certain special conditions. What are the conditions in question? Before answering, I shall enumerate certain points, concerning which we shall not seriously disagree.

1. Steam disinfection is the most efficient for the disinfection of mattresses, palliasses, feather beds, carpets, and all heavy articles that are not too greatly damaged by steam.

2. Saturated steam under pressure is the most rapidly effective method of applying steam.

3. Current steam is efficient, but in the machines as yet available for heavy disinfections it is not easily applied.

4. For blankets and woollen articles generally, the simplest method is steeping, in a known disinfectant and subsequent washing or rinsing in hot water. Steam in any variety is too apt to fix stains and to yellow the goods.

5. For articles of clothing (like tweeds) that are not too much shrunken by passage through steam, steam disinfection is simplest.

6. For all linen and cotton articles, the simplest method is steeping in a disinfectant and washing.

7. For all utensils and washable furniture, the simplest method is washing of surfaces with suitable disinfectants-non-corrosive for metal or polished articles, corrosive or non-corrosive for others.

8. For floors and all washable fittings, the same method of washing with suitable disinfectants is simple, and so falls in with ordinary household habits as to be safely relied on for execution.

9. For skins, furs, fur rugs, books, papers, pictures, silks, delicate bric-à-brac, and many articles not, as a rule, plentiful in the majority of houses requiring disinfection, some other method thain washing must be found.

10. The disinfection of the air in rooms is an affair of no practical account, since in most houses the foul air can be cleared out in a few minutes. To waste time in disinfecting air; which so

* Read before the Scottish Branch of the Incorporated Society of Medical Officers of Health, December, 1899. 
far has not been monopolized by any class, is, except for the special ends of special experiments, to play at disinfection.

11. There is, I take it, no serious disagreement about the methods of disinfecting sinks, water - closets, cesspools, latrines; but here there is room for much variation in practice, and the method chosen will, to some extent, depend on our choice of a dis. disinfectant.

12. There remain the walls of infected rooms. On this point there is a general wavering of opinion, which is reflected in un. qualified differences of practice. The purpose of this discussion is to sssist us in bringing our practices into line with scientific opinion. While, therefore, several of the matters enumerated offer room for differences of detail in practice, the only matter where practical methods so far diverge as to throw doubt on the efficiency of some of them is the disinfection of walls of infected rooms. . Our problem, therefore, is : What is the simplest, quickest, and cheapest method of disinfecting the walls of infected rooms? A subsidiary problem is: How to disinfect papers, furs, and such other delicate articles as I have named.

II. Assumptroxs. - In so stating the case, I have made certain assumptions. These are problems of detail.

1. I assume that a room where any case of small-pos, typhus, measles, chicken-pos, influenza, and other such rapid infections, remains for any period from a fow minutes to a few weeks, may retain infective elements on the walls.

2. I assume, however, that the liability so to retain infection varies directly with the time of exposure.

3. As a consequence, to make such a room safe it is essential to disinfect the walls.

4. I assume that a room where a case of scarlet fever, diphtheria, or: phthisis has been nursed for periods varying from days to months is liable to retain infection; but the risk of infection of walls is not equal in all. In scarlet fever the risk of wall-infection is small if the case has been removed within forty-eight hours of invasion; the risk is greater the longer the patient remains. This is not to foreclose the question of the infectivity or non-infectivity of the skin. Then diphtheria, properly nursed, is not very liable to infect walls; but the capacity of the Klebs-Löfler bacillus to live in dust for periods varying from 40 to 100 days makes it essential to disinfect the walls, if the room is to be certified free of infection. As to phthisis, the risk of wall-infection is small, if the case is well housed and well nursed; where it is neither, the risk is sufficient to justify very detailed disinfection. 
5. I assume that the other principal infections-enteric fever, puerperal fever, septicæmia, erysipelas, and the like-are not very liable to infect walle. But this leaves us small-pox, typhus, measles, chicken-pox, influenza, 'scarlet fever, diphtheria, phthisis, and a few others.

6. I assume that the retention of infection by the walls is a practical danger. The evidence I have been able to find that infected walls by themselves alone have actually given rise to fresh cases is very feeble; but I am not prepared to take the responsibility of declaring that such infection as walls may. retain is of little importance. We must assume that all the parts of the room -floor, walls, ceiling, fittings, and furniture-are possible sources of fresh outbreaks. In the more violent infections, like small-pox and typhus, there cannot be a reasonable doubt of the danger from walls. Where the walls are foul the danger is all the greater. In the other infections the danger may be less; but it cannot be neglected. No medical practitioner would risk the placing of scarlet fever cases in a ward recently saturated with measles ; nor would he risk a measles case in a recently-occupied scarlet fever ward. It would not be legitimate practice to place an enteric patient in an undisinfected typhus ward, or a diphtheria case in an undisinfected scarlet fever ward, or a healthy patient in an undisinfected smallpox ward, or, generally, any case of one major infection in an undisinfected ward recently occupied by a case of another major infection. Let us except enteric, erysipelas, and one or two other infections less readily conveyed by air. If it is not legitimate practice in hospital wards, where ventilation is good and cleansing frequent, still less legitimate is it in crowded rooms, where ventilation is bad and cleansing a pious aspiration. I lay stress on the point because sometimes the non-occurrence of infection is taken as a final test of the efficiency of disinfection, if the room has been, say, "fumigated," and, on the other hand, as a proof of the non-necessity of disinfection, if the room has been left undealt with. Of course, the value of the result depends, first, on the nature of the infection; second, on the probability of its retention; thirdly, on the nature of the exposure subsequently incurred by any particular patient; and, fourthly, on the degree of susceptibility. In a matter where direct demonstration of infection is so difficult, we must take a wide survey of facts, and a particular negative result following nondisinfection cannot fairly be set against the fact that, by one mechanism or another, walls being one, many infections continue to spread. It is, for instance, asserted by Dr. Martin, Medical Officer of Health for Paris, that house epidemics have fallen in 
number since the present method of spraying walls and furniture and carpets with corrosive sublimate has been substituted for fumigation by sulphur. The facts are probsbly numerous enough to justify the conclusion.

One further assumption I have made. It is not a matter of indifference that the method shall be simple, rapid, and cheap. By simple, I mean easy of application by the disinfectors, and as free as possible from annoyance to the inmates of the house. By rapid, I mean rapid enough to enable the local authority to overtake its duties. In many places time is no object, either to the operators or to the inmates; but in towns rapidity is essential; otherwise work is left undone, or left to the hands of the unskilled. The most rapid method, therefore, is, other things equal, the most efficient on the whole. This one qualification rules out, for routine practice, the rubbing down of walls with bread, the stripping of wall-papers, and all such processes as involve a day's labour of, say, two or three men. Doubtless, in certain cases rapidity is of no moment; but for routine disinfection after our most familiar infections, I consider rapidity of execution essential to good administration. By cheap, I mean cheap enough to justify a local authority in bearing the expense of every disinfection required. These three qualities arealmost too obvious to need detailed justification, yet they are all factors that ought to be estimated in fixing on any method.

III. The yost suitable Disinfectants.-To be suitable for the disinfection of rooms, including floors, walls, ceilings, doors, windows, presses, recesses, pantries, papered walls, sized walls; painted walls, immovable furniture-as fixed beds, chests, wardrobes, etc.-a disinfectant must be efficient; it must not: destroy or corrode the surfaces to be disinfected, unless these are of no importance; and it must not bleach fabrics. Few disinfectants fulfil these conditions. But some are so exceptionally powerful that certain drawbacks must be accepted as the price for efficiency: 'Of many available, I name only the following, for they are well known and well tested : sulphurous acid, corrosive sublimate, chloride with hypochlorite of lime, lysol, carbolic acid with common salt, formaldehyde in gas or in solution.

Before dealing with these and the methods of applying them, I should like to dispose definitely of the proposal to use light and air as disinfectants.

(a) Light and Air:- In the Tenth Report of the. State Board of Health of the State of Maine (1898), all the leading results of all the leading disinfectants have been admirably compiled by Dr. 
A. G. Young, Secretary of the Board. The authorities summarized leave no doubt that light, when allowed to act, is a powerful germicide. Sunlight is the most powerful, diffused daylight has a distinct effect, and electric light, though less powerful than sunlight, is still not without effect if continuously applied. "Anthrax spores were destroyed in a few hours by the action of sunlight."* But Momontt found non-sporing anthrax bacilli " in' dried blood resisted the action of sunlight and air eight hours. . . . Anthrax spores resist the action of sun and air more than one hundred hours when dry." Geisler $\ddagger$ records Janowski's observation that " typhoid bacilli exposed to direct sunshine were nearly all destroyed in from six to ten hours." In cholera the results vary. Palermo found that three or four hours' exposure to the sun "sufficed to deprive the germs of virulence when tested on guinea-pigs." $\$$ Tuberculosis exposed to air and light loses its virulence entirely in from a few minutes to several hours.\| With other organisms somewhat similar results are recorded. But the obvious criticism of any practical method based on these laboratory results is that sunlight is beyond our control; that in none of our houses can sunlight be applied continuously to any one part for more than a very short period; that in our towns hundreds of thousands of rooms are never penetrated by sunlight at all; that even where sunlight can be used, it cannot be relied upon for the interior of rooms; that, in short, while sunlight is in every way excellent where and when it is available, it cannot be made the basis of a method for disinfecting rooms. For furniture it is more readily available, and should not be forgotten. Electric light might be made available. It could be shone into every crevice; it might be developed into a practical method; but the expense would be, at present prices, prohibitive, and the results no better than with much cheaper applications. Until, therefore, our houses and our towns are so constructed as to make it possible to flood them with light as with air, we may definitely say that light and air are not efficient substitutes for active disinfection by other means. No surgeon would rely upon either air or light, and I do not know any good ground for: encouraging the belief that, however potent in the purification of water or infected surfaces exposed to them, light and air, in the qualities and quantities available in our over-lived-in, infinitely-dusty, perpetually-refouled houses, can be relied upon to kill more than a

* Marshall Ward, Centr. fïr Bak., xiii. 568, 1893.

+ Annales de l'Inst. Past., vi. 21, 1892.

+ Centr. fiir Bak., xi. 161, 1892.

Maine Report, p. 291.

Koch, Ransome. Delépine, ibid. p. 292. 
minute fraction of the household germs. In the absence of all other methods, light and air, with much time and trouble, might be made efficient; but simplicity would not be a feature of a disinfection so conducted, and for routine work the method would have to be ruled out as too laborious in practice. But, apart from practicability, a sunlight method in a climate where sunlight may be available only for an hour a reek hardly admits of serious discussion.

(b) Air.-Above I have coupled light and air. Flushing a room with fresh air is alwrys a proper thing to do, and the disinfective results are probably great; but the fact that certain germs normally live in air, and certain others persist for periods varying from hours to months, negatives the proposal to be content simply with disin: fection by ventilation. The dust of any inhabited room will be found more or less germ-laden, whether ventilation be continuous or not. I have not found any evidence sufficiently strong to justify the assertion that a room infected with, say, scarlet fever, or diphtheria, or tubercle, or small-pox, is adequately disinfected by exposure to fresh air for a period that is reasonably within possible practice. Air and light are excellent artillery, but they do not render the fighting line superfluous. To leave them to do the work is practically to leave the battle to chance.

(c) Sulphurous Acid.-This brings us to our chief point in dispute: Shall we continue sulphur or discard it? So ancient and well established a custom as fumigation by sulphur-burning is likely to find some justification at the hands of science. And it does. In Dr. Robert Angus Smith's book on "Disinfectants and Disinfection" sulphurous acid gets a high place. Its capacity to prevent or hinder putrefaction is maintained. But the book was written thirty years ago, when exact bacteriological tests were not possible. In $\mathrm{N}$. de la Croix's table, reproduced in Dr. Lauder Brunton's "Materia Medica,"* sulphurous acid as a destroyer of doveloped bacteria comes fifth in the list-that is, after chlorine, corrosive sublimate, chlorinated lime, and bromine. The strength indicated for germicidal purposes is 1 to 2,009. But 1 to 190 is required "to prevent the reproduction of devoloped bacteria," as against 1 to 1,250 for corrosive sublimate, 1 to 431 for chlorine, 1 to 336 for bromine. No details are given of the organisms employed, and, in the light of subsequent researches by other observers, these figures must be taken as the high-water mark of sulphurous acid in solution when applied to putrefactive bacteria. The results seem to bo somewhat inconstant. As summarized by $\mathrm{D}_{1}$. Rideal, $\uparrow$ 
Vallin "found it perfect"; Arnould found 10 per cent. "an uncertain means of destroying spores" ; Miquel "could not kill germs in twenty days"; Dujardin-Beaumetz "found that 20 grammes of sulphur, as used in the official French fumigation, did not kill $B$. anthracis, though it sterilized tubes of vaccine"; Koch found both sulphurous anhydride (the dry gas) and sulphurous acid (when sprayed) insufficient to kill spores. ("Sterilized tubes of vaccine" I understand to mean that the vaccine lost its capacity to produce a vaccination vesicle.) Other names are given. In the Maine Report already quoted, Dr. Young gives some more precise details of Koch's work. Koch found: "In a practically gas-tight casket 1 per cent. by volume of sulphur dioxide will kill dry anthrax bacilli in twenty minutes when on threads and exposed to the direct influence of the gas, and that under the same conditions the bacilli are destroyed in two minutes when the threads are demp. Anthrax spores, however, were wholly uninjured by a four days' exposure to 6 per cent. of the gas. When dried cultures of sporeless bacteria, not more than from one-tenth to onehalf millimetre thick, were exposed in a room fifty hours to sulphur dioxide, none were killed. One hour after the sulphur was lighted the percentage of sulphur in the air was about 3 ; one hour later it was only 1.25 ; and twenty hours later 0.015."* Again: "In Sternberg's experiments sporeless bacteria were destroyed under favourable conditions"; but he admits that "the conditions of success are such that it appears almost impracticable to conform to them in practice on a large scale, and it is evident that much of the so-called 'disinfection' with this agent is a farce." + Thoinot, howover, maintains that for tuberculosis, glanders, typhoid fever, cholera, diphtheria, "sulphur dioxide has a disinfectant action." He recommends 60 grammes for each cubic metre. But "Wolffhügel found that twice this quantity cannot be trusted to destroy even sporeless infection in room-disinfection."§ Dr. Novy (acting for the State Board of Health of Michigan) found, by strict experiment in an almost gas-tight room, that "sulphur fumes possessed little or no action on most bacteria when in the dried state. If, however, the specimens are actually wet, they will be destroyed, except in the state of the resistant forms, such as the spore stage and tubercle bacilli. For tubercle bacilli or spore-containing material, wet or dry, it is of no value. It can be used for the disinfection of rooms which have been infected with ordinary

* Maine Report, p. 362.

+ "Disinfection and Disinfectants," 1888, Concord, p. 64.

† Maine Report, p. 363 . \$ Ibid., p. 364. 
disease organisms. From 3 to 6 pounds of sulphur must be burned in each 1,000 cubic feet of space. The evaporation of water in the rooms where the articles are to be disinfected does not suffice. The walls, floors, and articles in the room should be sprayed with water. The room should be made perfectly tight, and should be kept closed at least twenty. hours." If these conditions are essential to success, clearly sulphur fumigation \&s ordinarily carried out in this country is of little or no disinfective value. These conditions of efficiency take no account of the incidental disadvantages of sulphur-e.g., the bleaching of wall-papers and clothing.

The disagreesbleness of the vapour is neither here nor there. That is probably an advantage, not a defect, and some maintain that the compelling power of a disagreeable smell is the main justification for continuing fumigation. I do not deny the compelling power, but I have not much belief either in the immunizing effects of uninformed confidence or in the indirect ventilation insured by sulphurous smells. No method can finally rest on such an argument. The somewhat misnamed "moral "effect of fumigation will not kill germs, and that is the beginning, middle, and end of the question.

Clearly there is a variable factor somowhere. Klein suggests that certain germs-e.g., B. subtilis, Micrococcus urece-thrive in sn acid medium, and therefore sulphur may sometimes fail. It is certain that sulphurous acid is a powerful reducing agent, and therefore may act rather as a cleanser than as a disinfectant. But the results referred to are sufficient to make one hesitate before accepting it as reliable in the rough conditions of house-disinfection. It is on all hands admitted that the dry gas-sulphurous anhydride-is itself of little value as a germicide, even in the most favourable concentration, but it has been maintained by Dr. Rideal that the moisture in the air of British climates is, as a rule, sufficient to convert the inefficient anhydride into the efficient acid. This is somewhat slender ground to form the basis of a universal practice. So far, however, in favour of sulphurous acid.

On the opposite side I give one or tro facts. Professor Sheridan Delépinet found that when "large drops of typical tuberculous sputa were dried on pieces of paper and placed in various parts of the rooms to be disinfected ... sulphurous acid was perfectly harmless so far as the bacillus was concerned. The tuberculous matter resisted the effects of exposure to sulphurous acid for a very

* Maine Report, p. 365.

† Journ. of San. Instit., January, 1898, p. 403. 
considerable length of time, and showed. no marked loss of vitality or virulence." Dry chlorine gas produced little effect, but 1 per cent. hypochlorite of lime solution was found extremely potent: Even when anthrax spores were tried they were killed in a few minutes. It is a fair inference that both sulphurous acid and chlorine are most potent in solution. If these facts are so, it seems to me utterly futile either to rely on sulphur fumigation or even to use it as a preliminary when a house has to be disinfected for tuberculosis. Possibly the tubercle bacillus, as it resisted the ordinary methods of staining, is specially resistant to certain germicides, and therefore cannot be taken as typical either of staining or disinfection. Before, however, I come to the practical deduction I wish to make, I should like to give an instance to cover other than tubercle and anthrax, which, after all, are comparatively uncommon germs in routine disinfective work. In the Maine Report* are recorded some experiments with sulphur fumigation. The experimenters-Professors F. C. Robinson and B. L. Bryantwere testing the value of formaldehyde, and as a "comparative experiment in room-disinfection, 12 pounds of roll sulphur were obtained for one of the same rooms used in the aldehyde experiments. This has a capacity of rather more than 2,000 cubic feet. The sulphur was placed in an iron kettle, and this in a copper tank filled with water so that the water came up around the kettle above the top of the sulphur. The sulphur was wet with alcohol and set on fire, and the room closed as tightly as possible. Diphtheria and anthrax cultures soaked into bits of blanket were placed about the room, some free and others in packets. Twelve hours afterwards the sulphur was found still burning, and so the room was left closed for twenty-two hours. In the morning it was impossible to enter the room to collect the cultures until after the windows had been opened for some time. All the windows were covered with a henvy dew of sulphurous acid, and the Pétri dishes and cultures in the same way. Two or three litres of water had been evaporated and all the sulphur burned. Every one of the cultures grew luxuriantly after a day's incubation. This result was so decidedly positive that it was thought unnecessary to make further experiments with sulphur. It showed how utterly worthless this agent is by the side of formaldehyde disinfection, even when properly used in these large amounts." The contra-experiments with formaldehyde were not always absolutely successful, but the results were, beyond all comparison, better than anything I have referred to regarding sulphur. 
To bring this collation of discrepancies to a point: First, to bo of any real disinfective value, sulphur must be burnt in the presence of water or water-vapour ; second, the efficient agent is the sulphurous acid so formed; and third, the deposit of this liquid acid on the infected surfaces is the essential part of the whole process. These appear to me fair inferences from the facts I have described. But if the deposit of the liquid acid is the essential part, why not apply it directly to walls and other infected localities by a spray or jet? Surely burning sulphui' for hours is a very roundabout way of applying a liquid disinfectant to a wall. It is a vastly more simple matter to begin with the liquid and spray it directly on to the wall. Fumigation takes hours; spraying, to produce a much more definite and controllable result as to deposit of liquid, is a matter of minutes. That, however, raises the question, Is it worth while to spray on a liquid that stands the bacteriological tests so inconstantly? For my own part, I do not think it is, and the choking effect of the liquid acid would be even more disagreeable than formalin or hypochlorite of lime, both of which are demonstrably more reliable.

On the whole, therefore, after a fair estimate of disinfective value and practicability, I conclude that the time has now come for the discarding of sulphur fumigation. Personally, I discarded it for house-disinfection three years ago-that is, as soon as I was placed in executive control of such disinfection. For hospital-disinfection, I discarded it four years ago. I have not discovered any now facts that would lead me to revert to sulphur fumigation either for honses or for lospitals.

The detailed discussion of the remaining disinfectants I reserve for the completed paper. My endeavour here lras been to clear our minds on sulphur. The remaining points are: $(a)$ Which of the disinfectants to choose-corrosive sublimate, chloride of lime with hypochlorite, lysol, carbolic acid, or formaldehyde? (b) Which method of applying them to walls are we to choose-sponging, brushing, hosing, spraying, or, in the case of formaldehyde gas, evaporation of formalin, or repolymerizing of paraform, or partial combustion of methylic alcohol, or any of the other modes devised for flooding a room with formaldeliyde or glycero-formol? One point $I$ consider of importance in estimating any of these methods. In every case referred to, it is cubic space that is described, but if we displace the air by simple ventilation it is not cubic space that wo have to disinfect; it is superficial space; it is surfaces of walls, floors, ceilings, furniture, etc. In estimating the necessary quantities, therefore, even of a gas, the primary matter is not the cubic 
content of the room, but the superficial area of the sides, and if a way can bo found of applying the gas directly to the surfaces, it is absolutely immaterial whether the germicidal amount is present in the centre of the room or not. In the case of formalin, for instance, the gas is slowly liberated from the liquid applied directly to the objects. The liquid subdues the dust and fixes it in place. This fixation puts any germs temporarily hors de combat, so giving at once more time cor attenuation of virulence and less opportunity for new infection. - To lay the dust physically, therefore, is in a vast proportion of cases temporary, and it may be permanent, disinfection. Further, by the fixation of the dust the gas is concentrated at the infected points. The slower it is dissipated into the room, the better. If, therefore, any way can be devised of getting formaldehyde rapidly on to the walls or other infected surfaces, that way would have the preference. And what applies to formaldehyde npplies to any other soluble gas or solution capable of generating gas.

Further detail I reserve for the continuation of this paper.

Prevention of Tunerourosis, -Dr. Annis, Medical Officer of Health of Huddersfield, states in his Annual Report for 1898 that the resolutions on this subject adopted by the Corporation* axe receiving the support of the veterinary surgeons in the district, and also of many prominent cowkecpers, but that up to the end of the year (1898) the time had been too short for any definite evidence as to the value of such action. He states also that he has been interviewed on several occasions by representatives of the Milk Dealers' and Farmers' Associations, and that they practically all agree as to tho desirability of attaining the objects in view, but that in the opinion of the Association the question ought to be dealt with by a public and not by a private Act. The Milk Dealers' Association also brought before him the question of taking samples of milk from milk brought into the town by rail, and the method of following up this milk to its source. Dr. Annis advised the Sanitary Committeo that they should assist the Milk Dealers' Association, and endeavour to obtain a clause having the following effect in any Act amending the Food and Drugs Acts:

"Inspector, or other duly qualified person, under tho direction and at the cost of the local authority appointing such inspector or oflicer, should have authority to procure at any railway-station or. other place of delivery any sample of any milk in course of delivery to the purchaser, whether in or out of the district for which he is appointed, and shall submit the same to bo analyzed, and the same shall be analyzed by the analyst to the local authority, notwithstanding he is not the analyst of the district."

[We would observe that the suggested clause does not appear to us to differ materially from Section 3 of the Sale of Food and Drugs Act of 1879.-Ed. Public Health.]

* Seo Public Health, xi., p. 569 (May, 1899). 